\title{
VERWANTE EN SOORTGELYKE STRO- MINGE LANGS DIE ANABAPTISME IN IN DIE SESTIENDE EEU
}

\author{
DS. J. J. STEENKAMP
}

\section{Inleiding}

In ' $n$ omwenteling soos wat die Hervorming in die sestiende eeu teweeggebring het, is dit sekerlik verstaanbaar dat daar sommiges sal wees wat nie op die kruin van die branders sal ry nie, maar in die skuim van gewaande branders sal on dergaan en uitspoel. Die sestiende eeu het homself daartoe geleen om sodanige figure te laat opkom, omdat dit noodwendig was dat daar in die groot stryd om die waarheid, 'n aantal medestryders sou wees wat deelwaarhede tot absolutes sou verhef. Hoewel die Hervormingsgeskiedenis in hoofsaak die stryd van die Reformatore met die Roomse Kerk aandui, was daar die newestrominge wat heel gou die teenstanders van sowel die Hervormde Kerke as die Roomse Kerk gehuisves het. Naas die ongeveer "suiwer doperse" groep was 'n aantal figure te vinde van wie die spreekwoord sou kon sê: „soveel hoofde, soveel sinne."

Hierdie figure het gedagtes van verskillende herkoms in ' $n$ bont mengse! verteenwoordig: mistici, chiliaste, panteĩste, sosiaalrevolusionêre. Renaissance-geeste, moraliste, rasionaliste, sodat benaminge soos: "Die Linkervleuel van die Reformasie",1) „die radikale reformasie", .,Stiefkinders van die Christendom", ${ }^{2}$ ) almal maar net pogings kan bly om die uiteenlopende denk- en lewensrigtings van hierdie mense te karakteriseer. Almal dra egter spiritualistiese kenmerke wat die historikus vinnig laat terugblaai na die Montaniste, die Waldense, die volgelinge van Joachim van Fiore $( \pm 1130-1202)$, die Broeders en Susters van die vrye gees, asook ander mistieke en apokaliptiese bewegings. Heeltemal nuut was hierdie strominge in die geskiedenis van die Christendom dus nie, hoewel direkte verwantskap met die bg. voorreformatoriese opponente van die kerk nie altyd an te wys is nie.

Hoewel gepoog word om hierdie mense te klassifiseer, is ' $n$ uitstaande kenmerk dit, dat hulle ook onder mekaar met wyd-uiteenlopende menings verskil het. Gemeenskaplike besit was teenkanting teen en geringskatting van alle uitwendige middele, d.w.s. kerklike organisasie, sakramente, seremonies en selfs die Bybel as gesaghebbende bron van die openbaring. Die regstreekse verligting en leiding deur die innerlike lig van die Gees het by hulle groot

1) H. Fast, Der linke Flügel der Reformation, Bremen 1962.

2) J. Lindeboom, Stiefkinderen van het Christendom. 
waarde gehad, ja, selfs in sommige gevalle die openbaring deur die Woord oortref. Hoewel hulle dus tesame met die Hervormers vrye Bybelondersoek voorgestaan het, het hulle in hul gevolgtrekkings by heeltemal ander punte van die waarheid te staan gekom, omdat hulle die oortuiging gehuldig het dat elke mens in 'n direkte verhouding staan tot die Gees van God. Sekerlik mede as gevolg van hulle teenkanting teen die sakramente, is sommiges verkeerdelik onder die algemene klassifikasie "dopers" of ook „wederdopers" geplaas. $\left.{ }^{3}\right)$ Wat die kerkorganisasie betref, het hierdie mense hoogstens die vorming van 'n .gemeente onder die Gees", d.w.s. 'n gemeente van wedergeborenes voorgestaan en wou dus wegdoen met alle tradisionele, asook nuwe, reeds in vaste vorme verstarrende kerkorganisasies, daar kerkvorming slegs in belemmering vir die lewe in die Gees daargestel het.

Dit is dan ook verstaanbaar dat, wat die klassifikasie, groepering of tipering van hierdie mense betref, die menings van die geskiedkundiges uiteenloop. So maak Bakhuizen van den Brink die groot indeling tussen Spiritualiste en Antitrinitariërs. ${ }^{4}$ ) Heussi praat weer van die Misties-Spekulatiewe Rigtings en die Antitrinariërs. ${ }^{5}$ ) Balke onderskei tussen Libertyne. Antitrinitariërs, evangeliese rasionaliste en vrydenkers. ${ }^{8}$ )

Vir die doel van hierdie referaat, word die indeling en onderverdeling van Bakhuizen van den Brink grotendeels gevolg.

\section{Spiritualiste}

Onder die benaming ..Spiritualiste" word diegene verstaan wat, hoewel hulle aanvanklik met die Hervormers op die grondslag van die vrye Bybelondersoek gestaan het, mettergaan van hulle vervreemd geraak het a.g.v. ' $n$ meer geestelike verstaan van die openbaring.

In die Duitse lande was daar die "Schwärmer" oftewel fanatieke dwepers, in Frankryk die Libertyne en dan ook enkele figure wat meer enkelinge in hulle denke en optrede was.

\section{A. Schwärmer}

\section{Karlstadt (1480-1541)}

Andreas Bodenstein, 1480 te Karlstadt gebore, was kannunik aan die Allerheiligenstift, hoogleraar aan die teologiese fakulteit te Wittenberg en Luther se promotor in 1512. In September 1516

3) Karl Heussi stel Thomas Müntzer as die eerste groot agitator van die anabaptiste, vgl. K. Heussi, Kompendium der Kirchengeschichte, Tübingen 1971, parag. 85c. So Balke as ,,doperse radikale", vgl. W. Balke, Calvijn en de doperse radikalen, Amsterdam 1973, bl. 2. Vgl. daarenteen A. D. Pont wat daarstel dat Müntzer ",hom weinig oor die doop bekommer het" in A. D. Pont, Die Reg van Opstand by Thomas Müntzer, artikel in Tydskrif vir Geesteswetenskappe. Pretoria 1974, Jrg. 14/1 bl. 27

4) J. N. Bakhuizen van den Brink, Handboek der Kerkgeschiedenis, Den Haag 1967. Derde Deel, bl. 97 v.v.

5) K. Heussi, a.w., bl. 329 v.v.

6) W. Balke, a.w., bl. 10. 
word hy diep verontrus deur sy voormalige leerling toe Luther in 'n dispuut die werk waarop die middeleeuse leer van die bieg berus, wat as werk van Augustinus uitgegee word, as oneg verklaar. ${ }^{7}$ ) Dit het Karlstadt wakker geskud en na die dispuut van Luther se leerling, Bartholomeus Bernardi, begin hy self die werke van Augustinus bestudeer en word so vir Luther gewen. ${ }^{8}$ ) Sy eerste 151 stellings was nog rustig, die tweede groep van 97 wat meer polemies was, het geen rimpel op die geleerde watervlak veroorsaak nie, maar wel sy derde groep stellings. Daarmee tree hy dan toe tot die akademiese strydperk. Dat hy miskien nie heeltemal opgewasse was nie, word betuig deur die feit dat Luther in 'n brief aan Eck vra dat lg. nie te rof met hom (Karlstadt) te werk moet gaan oor die 406 stellings wat hy teen Eck se "Obelisci" geskryf het nie. ${ }^{9}$ ) Karlstadt was dus in die beginjare van die Hervorming 'n redelike medestryder van Luther.

Terwyl Luther op die Wartburg was, begin priesters te trou, iets wat Luther in sy geskrif aan die adel aangeraai het. Karlstadt wou die huweliksreg ook uitbrei na monnike en nonne. Verder wou hy ' $n$ algehele opheffing van die monnikewese. mede onder invloed van Luther se geskrif „De votis monasticis”. Karlstadt neem ook die leiding by die hervorming van die mis en aangesien die mis die sterkste teenspraak was teen die nuwe leer, was 'n hervorming hier dringend noodwendig. Uit 'n finansiële oogpunt was dit egter uiters moeilik, aangesien 'n hervorming van die mis die hele struktuur rondom die stigtingswese sou moes verander.

Onder invloed van Gabriel Zwilling beëindig die Augustyners die viering van die mis in Wittenberg, terwyl die situasie aldaar steeds onduideliker en oproeriger word. In Desember $1521 \mathrm{kom} \mathrm{dit}$ daar tot opstootjies deur burgers en studente. Karlstadt vier op Kersfees met ongeveer 2000 deelnemers die eerste evangeliese Nagmaal (Melanchton het reeds vroeër die Nagmaal sub utraque specie gevier, maar net met sy leerlinge). Hierdie viering waarop nog verdere sulkes gevolg het, was bevestiging daarvoor dat die nuwe leer se konsekwensies in die praktyk uitgevoer kon word. Dit word egter duidelik dat Karlstadt nie meer die radikale hervorming wat hy ingevoer het kon beheer nie. Die toestand is nog vererger deur die aankoms van twee Zwickauer profete, Niklas Storch, 'n lakewewer en 'n voormalige Wittenbergse student, Markus Stübner; albei aanhangers van Thomas Müntzer. Op 6 Januarie ontbind die Duitse Augustynerorde onder voorsitterskap van Wensceslau Link. Karlstadt ontwerp op die grondslag van Luther se „Ordnung eines gemeinen Beutels“ (armsorg), 'n „Ord-

\footnotetext{
7) Heinrich Boehmer, Der junge Luther, Stuttgart 1962, bl. 112.

$8)$ Heinrich Boehmer, a.w., bl. 138.

9) Heinrich Boehmer, a.w., bl. 177.

10) A. D. Pont, a.w., bl. 28.
} 
nung der Stadt Wittenberg" waarmee die raad van die stad die Hervorming op 24 Januarie 1522 wil reël en bevestig. Hierdie planne word egter deur ' $n$ beeldestorming in die waar gestuur. Die gesag van Luther word nou dringend nodig en hy keer op 6 Maart vir goed terug. Na sy vaspreke van 9-16 Maart word dit weer weer rustig. Die Zwickauer profete wyk uit die stad en Karlstadt word beperk tot sy leeramp aan die universiteit.

Deur hierdie gebeure word Karlstadt geĩsoleer en hy begin al meer 'n mistiese subjektiwisme aanhang. Hy verlaat Wittenberg, word prediker in Orlamünde, maar word uit Keursakse verban a.g.v. oproerigheid en beeldestorming. Nou voer hy 'n onrustige lewe van omswerwinge waartydens hy breek met alles wat uiterlik aan die kerk was (o.a. Strassburg en Rothenburg ob der Tauber). Sy breuk met Luther volg finaal nadat hy in 5 traktate in 1524 'n nuwe uiteensetting van die nagmaal gee. Hy bestry die consubstansiasie van Luther en lê die touto van die instellingswoorde só uit, as sou Christus daarmee op sy eie liggaam gewys het. Gevolglik deel hy die simboliese opvatting van Zwingli. Hy onderwerp hom aan Luther in 1525, leef in armoede in Keursakse, vlug weer 1529 en werk in Holstein en Oosfriesland. Vanweë sy fanatieke en mistieke opvattinge is hy as Schwärmer nie by die godsdiensgesprek te Marburg 1529 toegelaat nie. In Switserland vind hy asiel en leef daar as professor in Basel tot sy einde in 1541.

Die indruk ontstaan dat Karlstadt, wat aanvanklik tog 'n redelike medestryder van Luther was, deur lg. se afwesigheid tydens die Wartburg-periode in 'n leidende rol gedwing is, terwyl hy eintlik a.g.v. sy eie bekwaamhede maar 'n goeie volgeling kon wees. Dit was seker mede verantwoordelik daarvoor dat hy die dwaalweë gevolg het.

\section{Thomas Müntzer (1488-1525)}

Thomas Müntzer word vandag allerweë deur linkse teoloë en sommige mak Marxiste aangesien vir die vader van die teologie van die revolusie. Dat hy hierdeur verkeerdelik getipeer word, is duidelik aangewys deur prof. dr. A. D. Pont. Prof. Pont wys aan dat Müntzer, eerder as om die totale bestaande orde te wil afbreek en 'n nuwe utopistiese en gesekulariseerde orde te wil vestig, d.m.v. die revolusie en die uitroeing van die goddelose, die hele bestaande wêreld deur die swaard wil verkerklik. Daarvoor het Müntzer die nodige humanistiese opleiding gehad en was hy ook verder gevorm deur die laat-middeleeuse mistiek van Johann Tauber en die spiritualisties-apokaliptiese werk van Joachim van Fiore. Tydens Luther se dispuut met Eck te Leipzig 1519, word hy as volgeling van Luther gewen. In Mei 1520 word hy mede deur toedoen van Luther aangestel as prediker in die Mariakerk in Zwickau. Daar word hy beinvloed deur die Zwickauer profete, 'n groep waarin heelwat 
middeleeussektariese opvattinge voortgeleef het. Mettergaan het die opvatting dat die direkte ingewing van die Heilige Gees los van die Woord die openbaring ir: die hede voortgesit het, Müntzer heeltemal vervreem van Luther vir wie hy ook later as "das sanftlebende geistlose Fleisch zu Wittenberg" uitgeskel het. Luther se regverdigingsleer en Bybelgeloof word deur hom as ' $n$,,aus Bücher gestohlener Glaube" bestempel. Uit Zwickau verdrywe a.g.v. sy stryd met Egranus, probeer hy in Praag 'n klankbodem vind vir sy idees, maar word daar tot driemaal toe uit die stad verban. In sy Prager Manifest van 1521 word dit duidelik dat hy die Heilige Skrif nie as die Woord van God aanvaar nie, maar eerder die "lewende" Woord wat deur die Heilige Gees ingegee word. Sy apokaliptiese denkbeelde veroorsaak dan dat hy oral geen aanklank vind nie en uiteindelik in Allstedt as predikant van die Johanneskerk beland. Hier is hy tot 1524 teologies werksaam en rig hy sy „Verbond van Uitverkorenes" op, waarby die meeste burgers van Allstedt, die Raad van die stad, asook ongeveer 500 Mansfeldse mynwerkers aansluit. Dit is ' $n$ offensiewe verbond waardeur die militiae christi saamgesnoer word om die Koninkryk van God op aarde deur die nodige sosiale en politieke veranderinge te verwerklik. Die einddoel was om die bestaande corpus christianum te verkerklik en terug te voer na die oergemeente in Jerusalem. Daarvoor sou die swaard gebruik word, óf om te dwing, óf om uit te roei. Die onrustigheid en oproerige ontevredenheid onder die bywoner-boere, het 'n vrugbare teelaarde gevorm vir die gedagtes van Müntzer.

Sy Fürstenpredigt maak die owerheid op hom opmerksaam en hy word deur hertog Johan so ingeperk dat hy Allstedt in Augutus 1524 verlaat. Te Mühlhausen rig hy met medewerking van Heinrich Pfeiffer 'n "Ewige Verbond met God" op. Hy werk ook mee aan die Twaalf Artikels van Mühlhausen en die bekenstelling, sowel as die implementering daarvan. Gedwing om die stad te verlaat, beland hy tog maar weer daar in 1525, na 'n reis oor Neurenberg en deur SuidDuitsland. In Mühlhausen was die revolusie nou ryp. Sy brief aan sy vriende in Allstedt van April 1525 ontketen die stryd waarin meer as 180000 boere in 'n reeks slagte sneuwel, 'n mens kan sê, uitgeroei word. Müntzer en Pfeiffer word op 27 Mei 1525 buite Mühlhausen onthoof.

Müntzer, as die klassieke Schwärmer, leer dat die geloof nie alleen deur die studie van die Heilige Skrif gewek word nie, maar deur ' $n$ direkte inwerking van die Heilige Gees wat subjektief ervaar word. Elke mens besit die aangebore moontlikheid om die Gees só te ervaar. Hierdie moontlikheid is 'n band van gelykheid wat alle mense aan mekaar bind. Sy opvatting oor die soewereiniteit van die volk lei hom daartoe om te verklaar dat die gelowige verplig is om teenoor die wêreldse owerheid te gaan staan. As die eskatologiese Elia moet hy die volk lei om van hulle reg gebruik te maak om die 
wêreldlike owerheid tersyde te stel en so die wêreld tot kerk te maak, waar die uitverkorenes sou lewe in die Koninkryk van God, na analogie van die Jerusalemse oergemeente.

Soos prof. Pont aangedui het, is Müntzer dus toevallig die geestelike leier van die Boere-opstand, geen doper nie, en geen voorloper van die Marxisme nie. ${ }^{11}$ ) Die beste tipering van Müntzer gee prof. Pont as hy hom 'n .merkwaardige randfiguur in die geskiedenis van die kerk" noem. ${ }^{12}$ )

\section{B. Humanistiese Spiritualis}

\section{Sebastian Franck (1499-1542)}

Franck uit Donauwörth word getipeer as 'n humanistiese spiritualis. Hy was aanvanklik Roomse priester in die Bisdom Augsburg. Deur die Lutherse hervorming word hy vir die hervorming gewen en tree vir 'n tydlank as Lutherse prediker op in die omgewing van Nürnberg. Daar verkeer hy in humanistiese kringe wat hom beinvloed en ook sy weg in die latere tyd bepaal. In 1528 lê hy sy predikamp neer om 'n swerwersbestaan te voer. As vryskut volkskrywer woon hy 'n tydlank in Neurenberg en daarna in Straatsburg. Om sy radikale denkbeelde, is hy telkens vervolg en verdryf. Martin Bucer, wat bekend was vir sy gasvryheid, het in Straatsburg allerlei geeste ontvang. ${ }^{13}$ ) Op een stadium het Franck as seepkoker in Esslingen sy lewensonderhoud bestry. Daarna was hy skrywer en boekdrukker in Ulm en beland ten slotte in Basel. Anders as vuurvreters soos Müntzer is hy quiëtisties van gees. Hy vind geen aansluiting by formele kerkorganisasie nie, as gevolg van sy uitstaande Individualisme. Sy individualisme lei hom om skepties te staan ten opsigte van alles wat wêrelds is, dus ook die kerk, ampte en sakramente. Selfs by die dopers vind hy geen aansluiting nie, omdat dié te gou in 'n wettiese lewenshouding verval het. As spiritualis aanvaar hy die gesag van die Gees wat die waarheid uit die Skrif, (wat hy wel as die kenbron daarvan aanvaar) bevestig deur die inwendige Woord in die innerlike van die mens te spreek. Hierdie innerlik gespreekte Woord staan bo die letter van die Skrif. Daarom is van sonde en regverdiging nie veel by hom te vind nie, want die Christusin-die-mens doen die heilswerk en nie die Christus van Golgotha nie. Deur panteisties-mistiese spekulasie word die Bybels-reformatoriese Christologie asook die Triniteit as't ware uitgeskakel. Geloof beteken om aan God oorgelaat te wees, 'n mistieke oorgawe aan en opgang in die Godheid, deur Christus wat in die mens deur die innerlike lig van die Gees gebore word, dit wil sê die Woord wat in die mens vlees word. Daarom stel hy hom teen die gevestigde kerk soos ons

11) A. D. Pont, a.w., bl. 28-29.

12) A. D. Pont, a.w., bl. 17.

13) W. Balke, a.w., bl. 126. 
reeds gesien het en verlang hoogstens na 'n suiwer geestelike gemeente. Die ware Christendom mag deur geen wet of orde of reëls verstar word nie.

As geskiedskrywer was hy pessimisties - wysgerig, maar deur 'n mistieke spekulasie skou hy agter die verganklike wêreldgebeure die goddelike orde en volmaaktheid waarvan die geskiedenis slegs ' $n$ beeld is; dus 'n mistiek spekulatiewe metafisika. Sy geskiedskrywing in die werk van 1531 „Chronica, Zeitbuch unnd Geschichtbibell", is baie belangrik vir die begin van die akatolieke geskiedskrywing. Daarin het hy ook die skeurmakers en ketters behandel, wat die feit beklemtoon dat hy uiteraard ' $n$ voorstander vir verdraagsaamheid was. Die duidelikste daarstelling van sy denkbeelde. kom voor in sy werk "Paradoxa" van 1534. Hoewel self verdraagsaam, het hy nie met baie verdraagsaamheid van die groot geeste van sy tyd te doen gekry nie. Deur almal is hy afgestoot; selfs Erasmus het gesorg dat hy uit Straatsburg verdryf word. Calvyn se oordeel oor hom was: „un fantastique... sans cerveau et du tout insensé"14) - 'n fantastikus, sonder verstand en heeltemal mal.

Om Coornhert die vernaamste navolger en geesverwant van Franck te noem, lyk 'n bietjie vergesog.

\section{Caspar von Schwenckfeld (1489-1561)}

Caspar Schwenckfeld is van geboorte 'n edelman uit Ossig in Silesië. Geinteresseerd in die teologie, word hy 'n getroue aanhanger van Luther. Sy beginpunt is dus nes die ander spiritualiste by die Hervorming. Vanweë Luther se stryd met Zwingli oor die nagmaal, word Schwenckfeld van Luther vervreem. Hyself sien die nagmaal as 'n hemelse spys en drank; dus 'n geestelike nagmaalbeskouing. So was sy hele teologie ook geestelik, hoewel dualisties. Dit kom veral na vore in sy kerkbegrip, waar hy stel dat die kerk van die ware gelowiges in verstrooiing leef en alleen by God bekend is. Hierdie is dan ook 'n geestelike en onsigbare kerk, 'n beskouing wat hom tot 'n libertinistiese toleransie voer, oftewel word hy voorstander van algehele verdraagsaamheid. Die implementering van die verdraagsaamheid moet begin deur "n „Stilstand" in die teologiese en kerklike stryd. Hoewel hy in die aardse Christus die heil van die mensheid sien, lei sy spiritualisme hom tog tot 'n mistieke verstaan van die heiliging en redding. Deur die oorwinning van die sondige kreatuurlikheid, word die mens op 'n geestelike manier één met die hemelse Christus. Sy teologie het hom 'n felle teenstander van die Confessio Tetrapolitana gemaak, deurdat hy verskil het van die nagmaalsopvatting wat daarin vervat is. ${ }^{16}$ )

14) Aangehaal by W. Balke, a.w., bl. 209.

15) J. N. Bakhuizen van den Brink, a.w.. bl. 99.

16) W. Balke, a.w., bl. 144. 
Sy nagmaalsopvatting en Christologie wat geheel geestelik en selfs misties was, het dan ook daarvoor gesorg dat hy nêrens by die Reformatore aanklank gevind het nie. In die omgewing van Calvyn het Paul Volz onder die invloed van Schwenckfeld gekom, deur dié se nagmaalsopvatting. Aan sy bekering het Calvyn self ' $n$ groot aandeel gehad. ${ }^{17}$ ) Daarby het gekom dat hy enige verwantskap met die Dopers getoon het, sodat sy uiteinde sektevorming was. In Swabe en Silesië het hy klein groepies aanhangers gehad, die Schwenckfeldiane wat in apostoliese broederliefde en vroomheid geleef het. Hulle word in 1720 deur die Jesniete uit Silesië verdryf. Sommiges het by die Hernhutters aangesluit en andere het uitgewyk na Pennsylvania waar hierdie sekte vandag nog ' $n$ klein. kongregasionatistiese kerkgemeenskap daarstel. Die hoofsaak by hulle is die navolging van Christus, 'n regskape lewe en toleransie.

\section{Libertins Spirituels}

In Frankryk het die sekte van die geestelike Libertyne bestaan, wat nie verwar moet word met die party van die Libertyne in Genève ten tyde van Calvyn nie. Hierdie sekte is vermoedelik uit die Nederlande afkomstig en Bucer wat in Straatsburg allerlei geeste ontvang het, was aanvanklik nie teen hulle gekant nie. Hulle het dan ook veral uit die bestryding deur Calvyn bekend geword as ' $n$ sekte van mistici wat min of meer vir die hervorming gewin was. Hulle quiëtistiese mistiek het panteistiese trekke getoon. Calvyn bestry hulle in sy geskrif „Contre la secte des Libertins”, 1545. Daarin stel hy dat hulle 'n Enkele Gees fantaseer waardeur hulle die wese van die engele in die hemel, van die duiwels in die hel en die sondes van die mense verwoes. Hulle sê dat dit hierdie Enkele Gees is wat alles doen. Die Bybel is nie nodig nie. Die Gees is in die hele skepping teenwoordig, en die hele skepping word deur Hom gelei. Alles staan ook onder sy voorsienigheid en doen sy wil. Hierdie Gees bewerk ook alles. God is daarom dan ook die outeur van alles wat hulle doen. ${ }^{18}$ ) Wêreld en sonde word opgevat as die gevolg van 'n bedrieglike mening wat deur geestelike insig oorwin moet word. Die voorbokke van hierdie sekte, Antoine Pocquet en Quentin Thieffry word vriendelik deur Marquerite de Navarre aan haar hof in Nerac ontvang, waar hulle in 1543 ook verblyf vind. Hoewel Marquerite self geen Libertyn was nie, het sy hulle tog 'n gewillige oor geleen, aangesien sy self deur die invloed van Lefèvre d'Etaples (wat self deur haar beskerm is tot aan sy dood in 1536) ' $n$ neo-platoniese mistiek as agtergrond gehad het. Dit kom veral na vore in haar bundel "Marquerites" 1533 en veral dan die "Miroir de l'âme pêcheresse”.

1i) W. Balke, a.w., bl. 143 v.v.

18) C.R. 7, 183. 
Voorafgaande aan die "Miroir" dui haar "Discord estant en l'homme par la contrarieté de l'Esprit et de la Chair, et paix par vie spirituelle" ook 'n spiritualistiese gees aan.

Calvyn waarsku haar teen die Libertyne. In 1546 word Quentin te Ronen tereggestel.

\section{Humanistiese rasionalis}

\section{Sebastian Castellio (1515-1563)}

Sebastian Castellio uit Savoye word vir Calvyn se denkbeelde gewen en deur sy toedoen in 1542 aangestel as rektor van die Collège te Genève. Hy was 'n uitstaan de geleerde en onder sy leiding het die Collẽge goeie vordering gemaak. Aangesien hy sy salaris te klein gevind het vir sy groot familie. het sy toegang gesoek tot die predikamp. Die Klein Raad was sy aansoek goedgesind en het hom aanbeveel. Calvyn en die ander predikante het sy toelating egter geweier op grond van twee verskille met hom. Hy kon nie die interpretasie wat die Geneefse kategismus aan die hellevaart van Christus gee, aanvaar nie, op grond daarvan dat hy getwyfel het dat I Petr. 3:19 in die sin van die Kategismus uitgelê kon word. Verder het hy gemeen dat die Hooglied van Salomo nie tot die kanon gereken kon word nie, omdat dit ' $n$ onwelvoeglike gedig was waarin Salomo sy ontugtige liefdesgeskiedenisse verhaal het. ${ }^{19}$ ) Castellio het hierna ander werk gesoek en Calvyn het Viret gevra om hom in Lausanne aan 'n pos te help. Dit het niks ingebring nie en in April 1544 was hy weer in Genève waar hy sy aansoek hernu het. $\mathrm{Na}$ aanleiding van sy teksuitleg van 2 Kor. $6: 4$ by 'n gesamentlike sitting van predikante, waarby hy al die negatiewe eienskappe op Calvyn en diesynes betrek het, in teenstelling met dit waartoe Paulus oproep, naamlik om dienaars van Christus te wees, oordeel Calvyn dat hy die waartekens van 'n skeurmaker dra. ${ }^{20}$ )

Hy verlaat Genève en na 'n behoeftige tyd in Basel, word hy aldaar lektor in Grieks. Na die verbranding van Servet, tree hy na vore as vegter teen kettervervolging. Hy publiseer (1544) onder die skuilnaam Martinus Bellius sy prinsipiële boek: „De haereticis an sint persequendi multorum sententiae". Hierop antwoord Beza met sy „De heareticis a civili magistratu puniendis". Calvyn skryf sy "Defensio orthodoxae fidei de sacra trinitate" teen Servet se dwalinge. Castellio word bekend as voorstander van onbeperkte gewetensvryheid en verdraagsaamheid. In sy "De arte dubitandi et confidendi" word sy teologiese standpunt duidelik, naamlik dat deur die twyfel sal blyk dat die christelike godsdiens as geloof in die leiding van Gods Gees en gesteun deur die Skrif, in ooreenstemming

19) R. Schwartz, Johannes Calvins Lebenswerk in seinen Briefen, Neukirchen 1962, Bd. I, bl. 264 v.v.

20) R. Schwartz, a.w., bl. 275. 
is met die rede. Castellio was eintlik geen werklike spiritualis nie, maar het negatief gestaan teenoor uiterlike sake soos 'n sigbare kerk, sakramente en seremonies. Hy het dan ook 'n suiwere gewetegods diens voorgestaan.

$\mathrm{Na}$ die bloedbad van Vassy op 1 Maart 1562 toon hy weer sy ywer tot verdraagsaamheid as hy die Hugenote daartoe oproep in sy geskrif "Conseil à la France désolée".

\section{Antitrinitariërs}

\section{Sociniane}

Onder invloed van die kritiek van die skolastiek soos verteenwoordig deur Occam en met behulp van denkbeelde van die Renaissance, ontwikkel in groep Italiaanse geleerdes in dogmatiek waardeur hulle vrykom van die katolisisme. In hierdie proses gaan die hoofelemente van die Christelike leer, naamlik Triniteit, Christologie en die sakramente so te sê verlore. Tot hierdie beweging wat met Anabaptisme uit Switzerland versmelt, behoort mense soos Gribaldo, Blandrata, Gentilis, aldrie bekend uit die polemiese werke van Calvyn, asook Lelio Sozzini, die oom van Fausto Sozzini.

Na die verbranding van Servet, verlaat hierdie mense Switserland en vind tesame met ander Antitrinitariërs 'n heenkome in Pole en Seweburge.

Fausto Sozzini, wat deur die denkbeelde van sy oom Lelio gelei word, verwerp die leer van die Drie-eenheid vo!ledig en uit Switserland verdryf, volg hy die spoor van Blandrata oor Sewenburge na Pole waar hy uiteindelik die sogenaamde Ecclesia minor stig, wat die resultaat was van sy strewe om verskeie spiritualistiese en antitrinitariese groepe byeen te bring. Die sentrum van hierdie kerk was Rakow.

Die Socinianisme leer dat Christus deur sy sedelike voorbeeld en nie sy kruisdood tot verlosser geword het. Die inkarnasie en die Triniteit word heeltemal afgewys. Deur samewerking van die mens met die wil van God, word hy geregverdig. Christus, 'n mens, word deur raptus in coelum na God geneem, daar onderrig en Hy bring dan die hemelse leer wat deur sy wonders en opstanding bevestig word. Die kerk is die gemeenskap wat hierdie leer aanhang.

Die Socinianisme het na die verdrywing uit Pole deur die Jesuite veral in die Nederlande onder die Remonstrante navolging gevind. So het hulle geskrifte in Engeland die Unitarisme daar bevorder. Ook later op die Aufkläring het die Sociniane invloed uitgeoefen.

\section{Michael Servet}

Servet was die bekendste Antitrinitariër van die 16 de eeu. Waarskynlik in 1509/10 gebore te Tudela in Spaanse Navarre, waarheen sy vader van Villanueva in Aragon getrek het, was hy ' $n$ 
uitermate begaafde student aan die universiteite te Saragossa en Toulouse waar hy in die regte studeer het en ook geleer het om die skrif te waardeer. By Oekolampadius 1530 word hy tereggewys oor sy verwerping van die Drie-eenheidsleer. Hy word deur Bucer en Capito in Straatsburg ontvang, maar nes Oekolampadius, kon hulle nie daarin slaag om hom tot ander insigte aangaande die Drie-eenheidsleer te bring nie. Dit word veral duidelik uit sy geskrif „De trinitatis erroribus" wat in 1531 te Hagenau verskyn. As hy uit die Duitse lande verdryf word, gaan hy na Parys waar hy matesis en fisika bestudeer wat hy later in sy astronomiese studies gebruik tydens ' $n$ verblyf te Lyon. Terug in Parys bekwaam hy hom in die medisyne en word ontdekker van die klein bloedsomloopstelsel voorwaar ' $n$ begaafde mens.

Gedurende die jare ' 40 praktiseer hy as lyfarts van die aartsbiskop in Vienne, waar hy ook in briefwisseling met Calvyn staan. $\mathrm{Na}$ die publikasie van sy .Christianismi Restitutio" onder 'n skuilnaam, word hy ontdek deur die Inkwisisie en te Vienne tot die dood veroordeel. Hy ontsnap, en op sy reis na Italië oor Genève, word hy herken en na 'n proses waarin Calvyn as die hoofaanklaer opgetree het, tot die dood veroordeel en verbrand op 27 Oktober 1553.

Servet het die Drie-eenheidsleer verwerp. Hy het 'n neo-platoniese panteīsme aangehang wat hom daartoe gevoer het om die triniteit as ' $n$ driekoppige Cerberus te bestempel. Sy panteisme voer hom sover dat hy sê dat die Godheid selfs in duiwels woon. Die Godheid het sowel aan duiwels as aan hout en klip deel geword. In die godheid is nie drie persone aanwesig nie, maar eerder drie kragte. Hy was dus geen unitariër nie, maar eerder kind van Sabellius. Hy verwerp ook die kinderdoop as leer van die pousdom. Daarin toon hy doperse neigings. Uit die feit dat Christus die kinders slegs die hande opgelê het, sluit hy dat die kinders ook nie gedoop moet word nie, maar net so die hande opgelê moet word. Hy sterf met die woorde, "Jesus, Seun van die ewige God, ontferm u oor my", waarin sy oortuiging duidelik na vore kom.

\section{Besluit}

1. Afgesien van die Schwenckfeldiane en die Sociniane vind geen van die bespreekte figure navolging in die geskiedenis van die kerk nie. Dit was enkelinge wat eiesoortige rigtings ingeslaan het, rigtings wat ophou bestaan het met die sterwe van die verteenwoordigers. Geskiedkundig is hulle invloed dus slegs negatief en gevolglik kan van enige beroep op hierdie figure om op hulle stellings en standpunte ' $n$ nuwe teologie te bou. dieselfde negatiewe resultate verwag word. 